\title{
The Meaning of Awaiting Bariatric Surgery Due to Morbid Obesity
}

\author{
My Engström ${ }^{*}, 1$, Malin Wiklund ${ }^{2}$, Monika Fagevik Olsén ${ }^{2}$, Hans Lönroth $^{1}$ and Anna Forsberg ${ }^{3}$ \\ ${ }^{I}$ Department of Gastrosurgical Research and Education, Sahlgrenska Academy at Gothenburg University, Gothenburg, \\ Sweden \\ ${ }^{2}$ Department of Neuroscience and Physiology, Sahlgrenska Academy at Gothenburg University, Gothenburg, Sweden \\ ${ }^{3}$ Institute of Health and Caring Science, Sahlgrenska Academy at Gothenburg University, Gothenburg, Sweden
}

\begin{abstract}
Background: The understanding of the association between the objective conditions of health and the subjective perceptions of morbidly obese patients appears to be poor. The use of objective indicators alone produces results totally unrelated to the feelings and experiences of the bariatric patients studied. No study has approached the bariatric patient from both an inside and a preoperative perspective.

Purpose: The aim of this study was to investigate the meaning of awaiting bariatric surgery due to morbid obesity. Method: Twenty-three patients admitted to a Swedish University Hospital for bariatric surgery were included. Data were collected by interviews and the analysis was performed using the phenomenological hermeneutics method developed by Lindseth and Norberg.

Main Findings: Two structural thematic analyses revealed six main themes: experiencing food as a complex element in life, feeling hopeless regarding weight loss, living in fear of future sickness and death, living a restricted life, being ignored by health care professionals and hoping for control and opportunities. The informants experienced addiction to food and dependence on others for managing their daily life, which constituted an infringement of their freedom. Loss of control meant giving in to the desire for food, but also being subjected to stigmatizing remarks from persons in their environment or uncaring approaches from health care professionals.

Conclusion: Being scheduled for bariatric surgery meant developing an awareness of how completely dependent they were on surgery for their survival and prospective health. The scheduled bariatric surgery constituted tangible confirmation that weight loss and restored health were possible.
\end{abstract}

Keywords: Morbid obesity, awaiting surgery, inside perspective, phenomenological hermeneutics method.

\section{INTRODUCTION}

Today, obesity and bariatric surgery is well documented from a disease perspective, but we have little knowledge of the lived experience of awaiting bariatric surgery due to morbid obesity. The understanding of the association between the objective conditions of life and health and the subjective perceptions of the patients appears to be poor. The use of objective indicators alone, e.g. weight loss, produces results totally unrelated to the feelings and experiences of the patients studied [1]. Cohen [2] suggested that it would be useful for patients to state, prior to surgery, what changes they hope for, and to ascertain, during follow up, to what extent their goals were realized. To our knowledge, no study has approached the bariatric patient from both an inside and a preoperative perspective. Thorne and Paterson described the outside and inside perspectives [3], the former represents the symptoms of the disease based on patophysiology, while the latter involves the patient's view of the disease and consequences for his/her daily life. According to Toombs [4], the outside and the inside perspective can also be termed

\footnotetext{
*Address correspondence to this author at the Department of Gastrosurgical Research and Education, Sahlgrenska Academy at Gothenburg University, Gothenburg, Sweden; Tel: +46 3134284 04; Fax: +46 314118 82; E-mail:
} my.engstrom@vgregion.se the professional and the personal understanding of disease. These perspectives differ from each other in four respects:
- the focus on the current situation
- $\quad$ attitude towards the disease
- $\quad$ relevance, i.e. what is important
- $\quad$ perception of time.

In order to move focus from disease to illness and the patients' perspective, the aim of this study was to investigate the meaning of awaiting bariatric surgery due to morbid obesity.

Obesity is one of the fastest growing health issues of our time. According to the World Health Organization [5], approximately 1.6 billion adults worldwide are overweight, of which at least 400 million are obese (BMI > 30). The WHO classifies the increased prevalence of obesity as a worldwide epidemic, and it is probably one of the greatest threats to wellbeing and health in developed countries. Obesity significantly increases the risk of co-morbidity (heart disease, diabetes, high blood pressure, stroke and most forms of cancer). However, not only is physical health negatively affected but mental wellbeing and psychosocial functioning also deteriorate [6]. Despite many traditional non-surgical weight loss attempts such as various exercise 
regimens, diet, medication and psychotherapy, the results are poor and the patients usually regain any weight they have lost [7]. The only method with a long-lasting effect on weight reduction is surgery of different types, classified as "bariatric surgery" [8]. Although there are certain risks associated with undergoing surgery, they are limited compared to the benefits that weight loss involves for severely obese individuals [9]. The number of bariatric procedures in public hospitals in Sweden was approximately 1500 in 2006, but considering that 175000 Swedes have a BMI that would necessitate surgery, a conservatively estimated calculation indicates the need for around $10-$ 15000 procedures per year in Sweden [10]. The WHO [5] estimates that 2.3 billion adults will be overweight in 2015 and that some 700 million will be obese.

What we already know is that bariatric surgery patients constitute a fast growing, relatively new population for many hospitals and health professionals as well as presenting a caring challenge because virtually every aspect of their treatment is affected by their size [11]. The strong negative social stigma due to obesity is also well documented, and a number of myths and assumptions surround eating and obesity [12]. Likewise, there are numerous publications available regarding obesity as a disease, its mechanisms, comorbidities, interventions and prevention in developed countries [5, 9]. To our knowledge, only a few studies, performed postoperatively, have explored the patient's own perceived experience of the bariatric surgery procedure [1318]. These studies report that surgery was viewed as a last resort for providing structure in life. Many patients experienced higher self-esteem and increased energy, as well as better control over their eating behavior and an overall change in their relationship to food after surgery. This in turn transformed the perception of their health status. All these changes could be achieved through an improved sense of control after surgery [15-17]. Some patients felt as if they were reborn and had undergone a transformation [13, 19], while one described it as totally different but still evolving, but adding that one must be careful who you tell because the stigma continues [14]. In an extensive literature review, Van Hout et al. [20] concluded that it is important for health care providers to identify aspects of a patient's psychological make-up, personality and eating behaviours that are relevant to his/her adjustment after surgery, so that various interventions can be used to improve prognosis. According to Gentry et al. [21] and Rydén et al. [22], patients' ability to adjust their eating behaviour and comply with dietary rules will determine the long-term outcome.

\section{MATERIALS AND METHODS}

\section{Participants}

In total, a group of a consecutive series of 23 pre-op Swedish patients (14 women and 9 men) with a mean age of 40.9 years (range 21-62) and a mean BMI of $52.2 \mathrm{~kg} / \mathrm{m}^{2}$ (range 38.4-67.6) were included in the study. Inclusion criteria were: admitted to a Swedish University Hospital for bariatric surgery (indications for surgery adhered to the criteria from The National Institutes of Health 1991) [23], aged between 18 and 65 years and Swedish speaking. All participants fulfilled the inclusion criteria. Details are presented in Table 1. All respondents were invited by letter to participate in the study. Informed written consent was obtained. The time and place for the interview was agreed by telephone. All respondents were interviewed at the hospital.

Table 1, Patient Characteristics for 23 Patients Being Morbidly Obese and Awaiting Bariatric Surgery

\begin{tabular}{|l|c|}
\hline Sex (Female/Male) & $14 / 9$ \\
\hline Age, years in median (range) & $40,9(21-62)$ \\
\hline BMI, $\mathrm{kg} / \mathrm{m}^{2}$ in median (range) & $52,2(38,4-67,6)$ \\
\hline Heart failure or infarction & $4 / 23$ \\
\hline Hypertension & $5 / 23$ \\
\hline Dyspnoea & $2 / 23$ \\
\hline Back pain & $5 / 23$ \\
\hline Pain in feet, knees and/or hips & $13 / 23$ \\
\hline Sleep apnoea & $3 / 23$ \\
\hline Diabetes & $6 / 23$ \\
\hline Patient with $>$ two co-morbidities & $5 / 23$ \\
\hline Gainfully employed & $14 / 23$ \\
\hline Disability pension or sick leave & $7 / 23$ \\
\hline Student & $2 / 23$ \\
\hline Married or cohabiting & $14 / 23$ \\
\hline Single & $9 / 23$ \\
\hline
\end{tabular}

\section{Data Collection}

A phenomenological hermeneutic approach was chosen as the participants' lived experience was of interest in order to gain a deeper understanding of the meaning of awaiting bariatric surgery due to morbid obesity. Data collection was by means of interviews that were audio-taped and transcribed verbatim, and the transcripts were compared with the tapes to ensure the accuracy of the narratives. The interviews took the form of an open dialogue. The first question was "Can you please tell me about your reasons for choosing bariatric surgery?". Follow-up questions were posed including their expectations of surgery, explanations about reasons for obesity, how they viewed their body and themselves, consequences in daily life, eating behaviour and relationship to food. The interviews lasted between 20 and 60 minutes.

\section{Data Analysis}

A phenomenological-hermeneutic method inspired by Ricoeur [24, 25] and developed by Lindseth and Norberg [26] was applied. The method consists of three steps, the first being the naïve reading, in which interviews were read several times in order to become familiar with the text and reach an initial understanding [26]. In the next step, the structural analysis, the text was divided into meaning units in accordance with the aim of the study. The meaning units were then brought together and grouped into themes and subthemes. In the final phase, the comprehensive understanding, the text was read again, while reflecting on the themes pertaining to what it means to be awaiting bariatric surgery due to morbid obesity. The interpretation 
was guided by the authors' pre-understanding based on their extensive experience of working with bariatric patients, teaching in surgical nursing as well as knowledge of previous research. This pre-understanding was constantly reflected upon and reconsidered during the data analysis and interpretation process.

Trustworthiness is important in qualitative studies. To enhance credibility [27] and prevent retrospective distortion or misinterpretation, the participants' statements were followed up by new questions. Quotations were used in order to illustrate the participants' views. Conformability (neutrality) was achieved by our description of the different steps in the analysis process and of how the various themes in the structural analysis were created based on quotations. With regard to dependability and conformability, the full text of the interviews was read by all authors, and only statements relevant to the aim of the study were included in the final analysis. Transferability was ensured by the fact that the interviews were performed at about the same time interval before admission to the hospital ward for surgery. This makes it possible to transfer the findings to other patients who are awaiting bariatric surgery. The authors agreed that the presented interpretation was the most reliable, although alternative interpretations were considered.

\section{Ethical Considerations}

Approval to perform the data collection was granted by the human research ethics committee at Gothenburg University Hospital. Before the interview started, the patients were once again informed about the aim of the study and the data analysis, aspects of confidentiality and were given the opportunity to withdraw. Arrangements were made to refer the interviewee to a counsellor if necessary. Quotations in the Results section were carefully chosen in order not to reveal the identity of any participant or risk breeching confidentiality. We were unable to envisage any negative or harmful effects for the participants and at all times endeavoured to ensure that they were not exploited during the research process.

\section{RESULTS}

The findings involve two thematic structural analyses in order to comprehensively grasp the experienced meaning of awaiting bariatric surgery due to morbid obesity. The basic assumption behind the analysis was that the patient's mere presence in the hospital in order to be admitted for bariatric surgery implies a state of suffering due to many years of struggling to lose weight and having reached a point where no intervention other than surgery remained. The first naïve understanding of the interview text revealed that awaiting bariatric surgery involved loss of control, and the initial structural analysis covers the meaning of being in this state (Table 2). The findings are illuminated by quotations from the informants.

\section{The First Structural Analysis}

\section{Experiencing Food as a Complex Element in Life}

When analysing the interviews, a clear pattern of food as a complex element in life emerged. Food as a way of socializing with friends was mostly mentioned by the male respondents.
"I have always enjoyed food and cooking is great fun. One of my favourite pastimes is cooking good food. No one can accuse me of lousy cooking, that's for sure."

Table 2. Structural Analysis of the Meaning of Being in Loss of Control Over Food Among 23 Morbidly Obese Persons Awaiting Bariatric Surgery

\begin{tabular}{|l|l|}
\hline \multicolumn{1}{|c|}{ Sub Themes } & \multicolumn{1}{c|}{ Main Theme } \\
\hline \hline $\begin{array}{l}\text { Enjoying food and cooking } \\
\text { Experiencing addiction to food } \\
\text { Experiencing food as consolation } \\
\text { Desiring a mechanism to control eating }\end{array}$ & $\begin{array}{l}\text { Experiencing food as a } \\
\text { complex element in life }\end{array}$ \\
\hline $\begin{array}{l}\text { Experiencing failure } \\
\text { Experiencing negative and dissatisfied } \\
\text { feelings towards one's appearance } \\
\text { Blaming oneself for eating wrong }\end{array}$ & $\begin{array}{l}\text { Feeling hopeless regarding } \\
\text { weight loss }\end{array}$ \\
\hline
\end{tabular}

Several informants viewed their relationship to food as a form of abuse and some drew analogues with alcoholism.

"I view this as an addiction. In the same way as alcoholism is an addiction, I am addicted to food".

Some of them, mostly women, expressed that they used food as a consolation when feeling sad, angry or unfairly treated, but also when feeling happy or celebrating something.

"I eat when I'm sad, when I need comfort, when I celebrate or when I'm happy or hungry. Yes, that's my way. I have actually used food both in joy and sorrow. There are people who don't eat at all when they're sad, worried or in trouble. I eat a huge amount then".

Several of the informants expressed that they desired a mechanism in their body that could help them control their eating behaviour.

"I need this superior person telling me what to do. I view the operation as a superior person, since it will make my bowel smaller, thus I have to eat less. It may sound strange, but somehow my stomach will set the limit. Now my stomach tells me to eat more and more. I won't be like that after the operation, so I think it can help me a great deal and it will also give me health."

\section{A Feeling of Hopelessness Regarding Weight Loss}

Losing weight and regaining it involving feelings such as hopelessness was a common occurrence for these patients. They felt that this endless roller coaster of unsuccessful dieting could only be stopped with the help of surgery.

“... I kept on gaining weight all the time, and then I tried a large number of things and nothing worked, some things worked for a while, but then I gained twice as much weight..." 
"So, I've tried all other ways, and I had so many backlashes that I wanted a more lasting effect. So I thought that surgery was the only option."

When the patients thought of their bodies they experienced a very negative and dissatisfied feeling. They often avoided mirrors and rarely weighed themselves so as not to be confronted by their appearance. They felt hatred and disgust about themselves. These feelings were enforced by nasty and defamatory comments from people around them.

\section{"I hate mirrors." \\ “.. I have no idea, I haven't weighed myself for over a year until today and then I shut my eyes" \\ “... but you can see the glances (sigh), they hurt as much as words."}

Being obese often led to changes in self respect. They felt guilty about being unable to control their weight, and the overweight resulted in sadness and shame that sometimes led to social isolation.

“...I've eaten wrong, so I blame myself."

"You don't mix socially, it is difficult, and you lock yourself inside the apartment."

"You feel as if you are less valuable when you're obese."

“... I don't think I see myself as being as big as I actually am. I don't look at myself. I think I would bury myself and die if I did."

"... and when you finally realise that you cannot do it by yourself, it feels like a failure to have to undergo surgery - it shouldn't be necessary."

\section{The Second Structural Analysis}

A second naive reading and structural thematic analysis revealed that, besides their loss of control over food, the informants experienced restrictions in every possible area of life due to obesity, leading to expectations of control and opportunities as a result of the scheduled bariatric surgery. The second thematic structural analysis described the meaning of awaiting bariatric surgery (Table $\mathbf{3}$ ).

\section{Being in Fear Future Sickness and Death}

All the patients reported a deterioration in their health as a major reason for requesting bariatric surgery. That obesity leads to co-morbidities was clear to all participants and they were pessimistic about their own future health. Lack of health consisted of physical morbidity such as the development of heart disease, cancer and bodily pain related to joint, back, knee and foot strain.

".. then I have pain in my back and my legs and now I've also got pain in my hip. I just can't move and I feel that I don't want to go on like this." "there are medical reasons, I suffer from diabetes, hypertension and obesity, and together these conditions affect my future."

Table 3. Structural Analysis of the Meaning of Awaiting Bariatric Surgery Among 23 Morbidly Obese Persons

\begin{tabular}{|l|l|}
\hline \multicolumn{1}{|c|}{ Sub Themes } & \multicolumn{1}{|c|}{ Main Theme } \\
\hline \hline $\begin{array}{l}\text { Feeling like having had enough } \\
\text { Experiencing present illness } \\
\text { Being afraid of further illness }\end{array}$ & $\begin{array}{l}\text { Being in fear of } \\
\text { prospective sickness } \\
\text { and death }\end{array}$ \\
\hline $\begin{array}{l}\text { Experiencing limitations in everyday life } \\
\text { Being unable to manage a job } \\
\text { Lacking energy to play with one's child } \\
\text { Being afraid of losing one's spouse } \\
\text { Experiencing insult from people around } \\
\begin{array}{l}\text { Feeling no hope to find clothes that fit } \\
\text { Feeling discriminated on the employment market }\end{array}\end{array}$ & $\begin{array}{l}\text { Experiencing a } \\
\text { restricted life }\end{array}$ \\
\hline $\begin{array}{l}\text { Feeling disinterest from the caring staff } \\
\text { Experiencing difficulties to get the right treatment }\end{array}$ & $\begin{array}{l}\text { Being disregarded by } \\
\text { professionals }\end{array}$ \\
\hline $\begin{array}{l}\text { Needing something to control one's food intake } \\
\text { Hoping to manage more } \\
\text { Hoping to play a part in society again } \\
\text { Hoping to survive }\end{array}$ & $\begin{array}{l}\text { Expecting control } \\
\text { and opportunities }\end{array}$ \\
\hline
\end{tabular}
up.

Other narratives described feelings of anxiety and giving

"..sometimes you get these feelings, I get anxious and am tired of everything. It becomes harder and harder".

They expressed fear of sickness, and some of the patients predicted a premature death if they failed to lose weight in the near future.

“... but after the cardiac infarction it started to get serious. If nothing changes, another infarction will occur and if there are still no changes then, maybe a wheelchair, maybe I will go blind..."

\section{Experiencing a Restricted Life}

Restriction in daily life was a general experience among the informants. Being unable to take care of home and hygiene was one aspect.

"It is difficult to put on your socks and shoes, to wipe yourself after being to the toilet, difficult to get out of bed".

Dependence on others was also common.

"He has to do the cleaning, I haven't enough strength and he does the shopping"

Planning the day to avoid unexpected events and embarrassing situations caused by the obesity was one common strategy.

"If I'm going out somewhere to deliver something [books], I have to plan how best to 
get there, so that I don't half kill myself carrying those bags of books."

A majority of the informants experienced a restricted life when it came to family, friends and society.

"I suppose it's my overweight that caused my back and knee problems, that's why I was made redundant from work a couple of months ago. I can't handle the work anymore".

They felt sorry about being unable to play with their kids,

"because right now I have to live and I want to spend time with my child and maybe do things. I can't even go and take a swim in the public baths."

or afraid of losing their spouse.

"and to be perfectly honest I am really disgusting, and it's not easy when you're this big, so there's a risk that my wife will leave me".

The informants were often subjected to social stigmatization, and people made hurtful comments about their looks and weight.

"I was going through a door when some young people in front of me didn't hold it open and I became annoyed and commented on it. Then one of them turned around, stared at me and said: 'You fat old hag, why don't you practise opening the door yourself?' Then I became thrown over and looked at myself. Am I that fat? At moments like that I become upset and angry and might buy myself a chocolate bar".

One problem that created a feeling of hopelessness was difficulty finding suitable clothes.

"To buy clothes, I have no idea what my style is. Today I buy anything that fits. Oh, over there was something nice, but of course it's not suitable for me, I don't want to be so limited."

They also felt discriminated against on the employment market.

"I missed out on one job, I think it was because of my obesity, they didn't spell it out, but I suspect it because I had the other qualifications they were looking for."

\section{Being Ignored by Health Care Professionals}

Due to their failure to do anything about the obesity and related problems, the informants often had the impression that care staff had little interest in them.

"There's always this incidental comment about my weight. Then I feel insulted, get angry and upset and say that of course I need to lose weight and then I go and buy a bar of chocolate afterwards. There you have it, the need for consolation again, when I'm angry, sad or have been insulted".
They shared experiences that it had been difficult to obtain the right treatment for their obesity, and irrespective of what disease or illness they sought help for, they were always advised to lose weight.

"The only answer they give me is that if I lose weight my back will be fine. That's my experience. And if I tell them that my arm is broken, they say: lose weight and your arm will be fine. I have encountered that attitude both from physicians and other health care professionals",

\section{Expecting Control and Opportunities}

A major reason for choosing surgery and feeling motivated about it was the sense of loss of control caused by obesity. The patients often reported that they had no control over their eating pattern, leading to uncontrollable weight gain.

“... and gain control over food.... When I eat, I eat a lot..... since I have such a large stomach it's difficult to control it just by my brain... so I feel that I need something..."

Another reason for applying for surgery was the hope of getting more out of life itself, an energy catalyser thanks to more normal weight, i.e. becoming more physically active and able to to obtain or keep a job.

"... you can manage more... be able to do things I haven't been able to do before”

" to get a job and be able to go to town and so on."

A well functioning social situation in the family, with friends and playing an active part in society was something that the informants were hoping to achieve with the surgery and subsequent weight loss.

"Losing so much weight that you can join your friends playing indoor hockey"

“... being able to do things I couldn't manage before... silly things like just running after a ball."

One fundamental wish was also to simply survive.

"I have a little boy and I would really like to survive and see him grow up".

\section{Comprehensive Understanding}

Awaiting bariatric surgery was interpreted by the patients as an experience involving loss of control in relation to food and a feeling of hopelessness regarding future weight loss unless operated on. They experienced a state of addiction to food and dependence on others for managing their daily lives, thus constituting an encroachment on their freedom. Loss of control meant having no power over the desire for food, but also being subjected to stigmatizing remarks from persons in their environment or uncaring approaches on the part of health care professionals. Being scheduled for bariatric surgery meant coming to a realisation of how completely dependent they were on it for their survival and future health. The serious condition of the patients due to obesity meant that they were unable to look at themselves 
without shame, guilt and even disgust. This meant enduring until bariatric surgery made it possible for them to escape their perceived predicament. The hope of seeing their children grow up, the ability to socialize with friends, take part in various activities and keep or obtain a job not only nurtured a desire to lose weight by surgery, but also the belief that they would recover and regain their freedom and independence. For the patients, the scheduled bariatric surgery constituted concrete confirmation that weight loss and restored health were possible.

\section{DISCUSSION}

\section{Methodological Considerations}

One limitation was that the informants came from the same hospital, implying that the results reflect only one medical and caring tradition. The results may have been different had patients from other hospitals also been included. Nevertheless, it is not the medical treatment itself that is under evaluation, but the experienced meaning of awaiting bariatric surgery due to morbid obesity. We argue that these experiences might be transferable and in some aspects universal, irrespective of the bariatric surgery setting. Phenomenological hermeneutics contributes to a deeper awareness of the perspective of the human subject by showing how knowledge can increase through describing, interpreting and understanding the experiences and expectations of patients who require surgery due to morbid obesity. When designing this study, one of the main questions was how to best obtain knowledge about morbidly obese patients' experiences prior to bariatric surgery. In spite of the burden of stigma, the only group able to provide such information comprises the patients involved. In line with Kvale [28], we took account of the asymmetric power relation inherent in interviews. Having reflected on the power dynamics, we are satisfied that the knowledge obtained was not misused during the interpretation and presentation of the data. The open-ended questions meant that the participants could answer in a way that they felt relevant to the situation as well as describe their thoughts and feelings about their obesity. Their descriptions were often vivid, despite the fact the they had previously experienced many negative caring encounters. The researcher who conducted the interviews has many years' experience of caring encounters with morbidly obese patients and tried to establish a relationship characterized by trust in order to gently probe this topic. We are satisfied that the data collection procedure and method employed were appropriate and that, by the use of a new perspective on this particular patient group, a deeper understanding has been achieved.

\section{Reflection on the Findings}

To our knowledge, no previous study has approached bariatric patients, preoperatively as well as from an inside perspective. Therefore these findings provide a unique and in-depth understanding of the meaning of awaiting bariatric surgery due to morbid obesity. Both outside and inside perspectives are important and valid; there is no contradiction between them. But it is essential to be aware of the different perspectives and above all one's own personal attitude [4]. Staff members expect the obese patient to adhere to nutritional restrictions after bariatric surgery, as well as advice regarding medical treatment and recommended life style changes. The patient, on the other hand, views the obesity in terms of the consequences for his/her daily life and interprets its meanings in a different way. We converse with and approach the bariatric patient from a reductionist perspective, with little knowledge of the perceived experience of obesity and deterioration in health status. We can capture the lived experiences of bariatric patients by obtaining their inside perspective by means of interviews.

When comparing our results with other qualitative studies [15-17], there are similarities when it comes to seeking bariatric surgery because of a deterioration in health, social life, the search for a stop mechanism for over-eating and surgery as a last resort. What have not been described before, or only very briefly, are the negative feelings about caring encounters. This study also adds new knowledge about the patients considering food as a substance that can be abused, by their use of words such as abuse and addiction when talking about their relationship to food. Also new is the patients' experienced lack of empowerment in their obese condition, where they were helpless due to their own lack of power to stop overeating, dependent on others to assist them in everyday life and on more or less prejudiced health care professionals. Almost none of the participants spoke about their own part in this treatment and of losing weight after surgery; as if there was a total lack of empowerment and that surgery itself would give them control over their eating, weight loss and life.

The participants viewed surgery as the last resort after several unsuccessful dietary treatments as well as a control tool for their eating habit, which is in line with Ogden et al. $[15,16]$. The importance of realistic and reasonable expectations of surgery is described by Van Hout et al., Walfish and Brown and Dalle Grave et al. [20, 29, 30]. Wysoker [17] discussed that when the structure of surgery is no longer present, reality sets in and the structure has to be replaced by lifestyle changes. Bocchieri [13] also highlighted the fact that surgery does not always lead to a simple and positive outcome. Several of her interviewed patients reported negative situations that occurred, such as existential questions, changes in relationships with spouses/significant others and various social relationships. We argue that it is important that patients are aware that surgery is not the only key to a successful outcome. Our role as caregivers is to encourage and support the patient to be more motivated in his/her treatment and have realistic expectations on surgery. This educational conversation should start before surgery.

It is of vital importance that we as caregivers listen to the patients' own experience, so that we can promote individual care. According to Buxton [31], this can be achieved by creating a therapeutic relationship by means of respect and a positive attitude, as in such a relationship the patients are more likely to share their experiences and expectations with the caregiver. If we understand the patients' preoperative experience and expectations on surgery, we can identify risk factors, e.g. overconfidence in the surgery itself, lack of empowerment in the treatment and "emotional eaters", all of which might be negative for an optimal pre- and post surgery care and weight loss. According to the literature, the reasons for obesity are multiple and complex and not simply a result of overeating. Caring for the obese patient seeking bariatric 
surgery is also a challenging task. Identifying the relationship between obesity and various other aspects is essential at the pre-operative stage, so that we can initiate the necessary interventions after surgery to achieve a successful long-term outcome. One of the most challenging findings in our study was the respondents' complex relationship to food, involving strong emotional aspects, and among other things leading to addictive behaviour. One aspect that might affect the long-term maintenance of weight loss is, according to Walfish and Brown [32], so called "emotional eaters"; patients who use food to overcome boredom, reduce stress and cope with depression. Bocchieri et al. [13] also described how patients who considered themselves "emotional eaters" had the greatest difficulties adapting their post surgery eating behaviour. We believe that identifying these patients before surgery can help us plan early interventions in order to achieve a successful outcome.

Considering food as a form of addiction brings to mind other similar conditions such as alcohol abuse, which was mentioned by several participants. Alcoholism is often viewed as a disease of denial, involving shame and guilt among the patients involved and leading to severe personal and social consequences. According to the Diagnostic and statistical manual of mental disorders, DSM IV [33], substance dependency involves tolerance, and the fact that the substance is used more often and to a greater extent than intended. There is also an enduring desire or unsuccessful attempts to limit or control the use of the substance. Several informants confirmed food abuse and there was a strong need for a stop mechanism to control their eating behaviour. All participants had made several attempts with various methods to lose weight, but always regained it along with some extra kilos.

The results of this study emphasize that the addictive aspect of obesity must be considered when assessing patients for bariatric surgery.

In many cases, a significant, underlying cause of morbid obesity is genetic, and it should be emphasized that obesity is not a weakness but a disease that is largely caused by a person's genetic makeup [7]. However, in this study, many participants explained their obesity by food and overeating, leading to severe consequences that negatively affected daily life. No participant claimed that his/her genetic makeup was the cause of his/her obesity and illness.

The caring encounters reported in this study were mainly negative. The health care professionals, i.e. nurses, were unable to acknowledge or confirm the true suffering of these patients, regardless of the level of care. Here, guidance could offer a real opportunity to better care for these patients. However, the patients do not want guidance that only provides superficial information about diet, exercise or medication. Such guidance only makes things worse, leading to increased food intake and a more negative self-perception. Thus, there is a need for courageous nurses and other professionals who dare to examine the problems in depth, in order to find out what is really essential for the morbidly obese patient. According to Fagerström et al. [34], a nursing deficiency that takes the form of not noticing or understanding the patient's desire for confirmation can be a sign of lack of courage, lack of compassion, lack of ability to interpret the patient's signals and insufficient knowledge of existential matters. When starting an obesity surgery programme, the care environment will require several modifications as well as certain items of obesity-related equipment. However, it is also of vital importance to address and discuss obesity bias among staff members, as they have an obligation to understand, accept and project a professional attitude towards the morbidly obese patient [34]. It is a delicate task to find out what problems, needs and desires are hidden under the surface or behind attitudes without violating the patient's dignity. Even during assessment, we believe that a multi-professional approach is essential in order to comprehend the complexity of the patient's perceived suffering.

In conclusion, the reported consequences of obesity in daily life were extensive. Since obesity is a complex disease, we believe it is vital to involve significant family members at an early stage of the caring process. A next of kin could act as a coach during all phases before and after bariatric surgery. The clinical nurse specialist or the primary nurse could be responsible for identifying suitable support persons among family members, relatives and/or friends. When caring for a pre op bariatric patient it is important to ensure that he/she has realistic goals in relation to surgery, or there is a risk that he/she will regard it as another failure.

Suggestions for further research include studying the strategies used by next of kin or relatives to approach the morbidly obese patient pre- and post surgery, as well as the obese patient's experiences of being obese as well as of normal weight. Other areas of interest are long-term follow ups after surgery, patients who were unable to maintain their weight loss or who did not have a successful outcome from surgery.

\section{REFERENCES}

[1] Najman JM, Levines S. Evaluating the impact of medical care and technologies on the quality of life: a review and critique. Soc Sci Med 1981; 15 (2-3): 107-15.

[2] Cohen C. On the quality of life: some philosophical reflections. Circulation 1982; 66 (Suppl. III): 29-33.

[3] Thorne SE, Paterson BL. Two decades of insider research: what we know and don't know about chronic illness experience. Annu Rev Nurs Res 2000; 18: 3-25.

[4] Toombs SK. The meaning of illness: a phenomenological account of the different perspectives of physician and patient. Philosophy and medicine. Dordrecht: Kluwer 1992.

[5] World Health Organization (WHO). Available from URL: http: //www.who.int/topics/obesity/en/ [Cited: 25 November 2010].

[6] Karlsson J, Taft C, Ryden A, et al. Ten-year trends in healthrelated quality of life after surgical and conventional treatment for severe obesity: the SOS intervention study. Int J Obes 2007; 31: 1248-61.

[7] Martinez OT. Overwiev of obesity. Crit Care Nurs Q 2003; 26(2): $162-5$.

[8] Sjostrom L, Lindroos AK, Peltonen M, et al. Lifestyle, diabetes, and cardiovascular risk factors 10 years after bariatric surgery. N Engl J Med 2004; 351(26): 2683-93.

[9] Spence-Jones G. Overview of obesity. Crit Care Nurs Q 2003; 26(2): 83-8.

[10] Näslund I, Boman L, Näslund E, et al. NIOK 2.0: Nationella Indikationer för Obesitas Kirurgi, S.K.o.L. Socialstyrelsen, 2009.(in Swedish) Available from URL: http: //www.sfoak.se/wpcontent/niok_2009.pdf [Cited: 25 November 2010].

[11] Blackwood HS. Obesity: a rapidly expanding challenge. Nurs Manag 2004; 35(5): 27-35.

[12] Reto CS. Psychological aspects of delivering nursing care to the bariatric patient. Crit Care Nurs Q 2003; 26(2): 139-49. 
[13] Bocchieri LE, Mean M, Fisher BL. Perceived psychosocial outcomes of gastric bypass surgery: a qualitative study. Obes Surg 2002; 12(6): 781-8.

[14] Earvolino-Ramirez M. Living with bariatric surgery. Totally different but still envolving. Bariat Nurs Surg Pat 2008; 3(1): 1724.

[15] Ogden J, Clementi C, Aylwin S. The impact of obesity surgery and the paradox of control: A qualitative study. Psychol Health 2006; 21(2): 273-93.

[16] Ogden J, Clementi C, Aylwin S, et al. Exploring the impact of obesity surgery on patients' health status: a quantitative and qualitative study. Obes Surg 2005; 15(2): 266-72.

[17] Wysoker M. The lived experienced of choosing bariatric surgery to lose weight. J Am Psychiatr Nurses Assoc 2005; 11(1): 26-34.

[18] Magdaleno R, Chaim EA, Turato ER. Understanding the life experiences of Brazilian women after bariatric surgery: a qualitative study. Obes Surg 2010; 20(8): 1086-9.

[19] Sutton DH, Murphy N, Raines AD. Transformation: The "LifeChanging" experience of women who undergo a surgical weight loss intervention. Bariat Nurs Surg Pat 2009; 4(4): 299-306.

[20] van Hout GC, Verschure SK, van Heck GL. Psychosocial predictors of success following bariatric surgery. Obes Surg 2005; 15(4): 552-60.

[21] Gentry K, Halverson JD, Heisler S. Psychologic assessment of morbidly obese patients undergoing gastric bypass: a comparison of preoperative and postoperative adjustment. Surgery 1984; 95(2): 215-20.

[22] Rydén O, Hedenbro J, Frederiksen S. Weight loss after vertical banded gastroplasty can be predicted: A prospective psychological study. Obes Surg 1996; 6(3): 237-43.
[23] National Institutes of Health Consensus Development panel (NIH). Gastrointestinal surgery for severe obesity. Ann Intern Med 1991; 115: 956-61.

[24] Ricœur P. Interpretation theory: discourse and the surplus of meaning. $8^{\text {th }}$ ed. Fort Worth: Texas Christian Univ Press 1976.

[25] Ricœur P. Oneself as another. Chicago: Univ. of Chicago Press 1992.

[26] Lindseth A, Norberg A. A phenomenological hermeneutical method for researching lived experience. Scand J Caring Sci 2004; 18(2): 145-53.

[27] Lincoln YS, Guba EG. Naturalistic inquiry. Beverly Hills: Sage 1985.

[28] Kvale S. Dominance through interviews and dialogues. Qual Inq 2006; 12(3): 480-500.

[29] Walfish S, Brown BA. Patient expectations of weight loss from bariatric surgery. Bariat Nurs Surg Pat 2006; 1(3): 205-10.

[30] Dalle GR, Calugi S, Molinari E, et al. Weight loss expectations in obese patients and treatment attrition: An observational multicenter study. Obes Res 2005. 13(11): 1961-9.

[31] Buxton B. Body image and women: How does obesity fit into the picture? Bariat Nurs Surg Pat 2008; 3(4): 285-90.

[32] Walfish S, Brown BA. Self-assessed emotional factors contributing to increased weight in presurgical male bariatric patients. Bariat Nurs Surg Pat 2009; 4(1): 49-52.

[33] Spitzer RL. DSM-IV casebook : a learning companion to the Diagnostic and statistical manual of mental disorders. $4^{\text {th }}$ ed. Washington: American Psychiatric Press 1994.

[34] Fagerstrom $\mathrm{L}$. The patient's perceived caring needs as a message of suffering. J Adv Nurs 1998; 28(5): 978-87.

(C) Engström et al:; Licensee Bentham Open.

This is an open access article licensed under the terms of the Creative Commons Attribution Non-Commercial License (http://creativecommons.org/licenses/by$\mathrm{nc} / 3.0 /$ ) which permits unrestricted, non-commercial use, distribution and reproduction in any medium, provided the work is properly cited. 